\title{
Keberadaan Bahasa Melayu-Kuna Abad VII- IX C Di Jawa
}

\section{Riboet Darmosoetopo}

Keywords: inscription, Melayu, distribution, origins, dating, hypothesis

\section{How to Cite:}

Darmosoetopo, R. (1998). Keberadaan Bahasa Melayu-Kuna Abad VII- IX C Di Jawa. Berkala Arkeologi, 18(1), 30-39. https://doi.org/10.30883/jba.v18i1.774

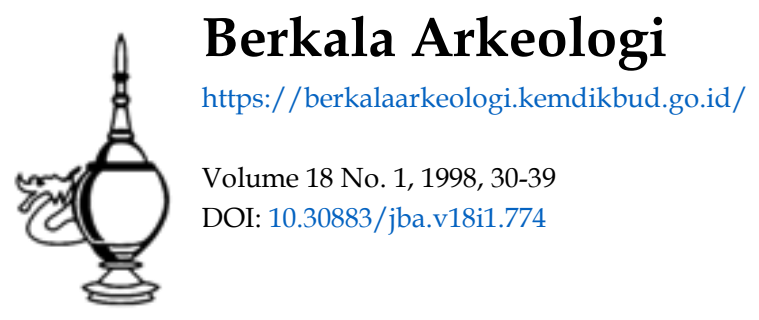

\section{c) (i) (5)}

This work is licensed under a Creative Commons Attribution-NonCommercial-ShareAlike 4.0 International License. 


\title{
KEBERADAAN BAHASA MELAYU-KUNA \\ ABAD VII - IX Ç DI JAWA
}

\author{
Riboet Darmosoetopo \\ (Jurusan Arkeologi - Fakultas Sastra UGM)
}

Prasasti sebagai peninggalan budaya dan sangat penting untuk dipergunakan dalam penulisan sejarah, ditemukan di seantero kepulauan Indonesia. Tetapi prasasti yang berbahasa Melayu-Kuna hanya ditemukan di Sumatra dan Jawa. Akhir-akhir ini ditemukan juga prasasti berbahasa Melayu-Kuna di pantai selatan pulau Laguna, Pilipina. Delapan prasasti berbahasa Melayu-Kuna dari masa Kedatuan Sriwijaya ditemukan di Sumatra. Kedelapan prasasti itu ialah prasasti Kedukanbukuit (605 Ç), Talang Tuwo (606 C)), Kota Kapur( 608 Ç), Karangbirahi, Telaga Batu, Boom Baru, Palas Pasemah, dan prasasti Bungkuk. Ketujuh prasasti berbahasa Melayu-Kuna yang ditemukan di pulau Jawa ialah prasasti Manjuçrigrha (714 C)), Payaman (700-750 Ç), Dapunta Selendra $( \pm 750$ Ç), Sang Hyang Wintang, Dang Pu Hawang Glis, Dewa Drawya (Dieng), dan prasasti dari Kebon Kopi. Sebuah prasasti dari lempengan tembaga, berbahasa Melayu-Kuna, beraksara Jawa-Kuna, bertahun $822 \mathrm{C}$ ditemukan di pantai Laguna (Kepulauan Pilipina Selatan). Timbul permasalahan tentang keberadaan bahasa Melayu-Kuna ini di Jawa baik mengenai proses maupun perkembangannya dalam kontilasi kesejarahan. Oleh karena itu dalam makalah kecil ini akan dicoba mengajukan gagasan pemecahannya meskipun masih bersifat hipotetis.

Dalam usaha pemecahan masalah itu akan dicoba melalui beberapa aspek, meliputi segi ruang, segi waktu, segi kebahasaan, maupun segi kesejarahannya.

\section{II}

\section{Tinjauan dari aspek ruang}

Prasasti-prasasti yang disebut di atas berbahan batu kecuali prasasti yang ditemukan di pantai Laguna (Pilipina Selatan) dan Prasasti Payaman (Bukateja, Purbalingga). Dari prasasti-prasasti yang berbahan batu itu menimbulkan asumsi bahwa mereka belum mengalami perpindahan dari tempat semula (apalagi terjadi pergeseran tidak jauh dari tempat asalnya). Dengan alasan itu maka ruang atau tempat ditemukannya prasasti perlu diperhitungkan dalam pembicaraan. 


\section{a. Sumatra}

Prasasti-prasasti berbahasa Melayu-Kuna dari Kedatuan Sriwijaya semuanya semuanya ditemukan di Sumatra atau pulau Bangka. Prasasti Kedukan Bukit ditemukan di tepi Sungai Tatang (anak Sungai Musi) di kaki bukit Siguntang, Palembang. Prasasti Karangbirahi ditemukan di Karangbirahi, di udik Sungai Marangin, Jambi. Prasasti Kota Kapur ditemukan di Kota Kapur, sebelah utara Sungai Mendok, Bangka. Prasasti Telaga Batu ditemukan di sebelah timur kota Palembang. Prasasti Bungkuk ditemukan di Jabung, Lampung Selatan. Prasasti Palas Pasemah ditemukan di Lampung Selatan. Dan akhirnya prasasti Boom Baru ditemukan di daerah Lampung. Berdasarknan tempat-tempat temuan prasasti itu didapat gambaran tentang persebaran budaya kedatuan Sriwijaya yang pada waktu itu meliputi Jambi, Palembang, Lampung, dan Bangka. Tentunya di wilayah sekitar tidak luput dari persebaran budaya Sriwijaya juga.

\section{b. Jawa}

Prasasti-prasasti berbahasa Melayu-Kuna yang ditemukan di Jawa ialah prasasti Payaman ditemukan di Bukateja (Purbalingga, Jawa Tengah), prasasti Dewadrabya ditemukan di Dieng, prasasti Dapunta Selendra ditemukan di daerah Temanggung. Prasasti Sang Hyang Wintang dan prasasti Dang Pu Hawang Glis, keduanya ditemukan di daerah Temanggung. Dan akhimya prasasti Manjuçrigrha ditemukan di candi Sewu (Prambanan). Dari tempat-tempat penemuan prasasti itu dapat diasumsikan persebaran perkayaan bahasa Melayu-Kuna di Jawa Tengah meliputi daerah Dieng sampai Prambanan.

Suatu yang menarik perhatian ialah di Jawa Barat hanya ditemukan sebuah prasasti berbahasa Melayu-Kuna yaitu prasasti yang ditemukan di Kebonkopi. Hal ini menimbulkan pertanyaan mengapa daerah Jawa Barat yang secara geografis berdekatan dengan Sumatra justru tidak banyak prasastinya yang berbahasa MelayuKuna. Padahal kerajaan Taruma dari abad V/VI M pernah berkembang di Jawa Barat dan meninggalkan beberapa prasasti berbahasa Sanskerta.

Pantai utara Jawa Tengah terutama wilayah sekitar Pekalongan sampai daerah Batang sarat dengan temuan benda purbakala terutama prasasti. Prasasti-prasasti itu berasal sekitar pertengahan abad VII (prasasti Gringsing)sampai dengan abad IX (Blado). Sedang disebelah barat dan timur daerah Pekalongan-Batang boleh dikata tidak padat temuan benda purbakalanya. Padatnya temuan benda purbakala di wilayah Pekalongan-Batang dapat dikaitkan dengan kompleks percandian Dieng dan Gedongsongo. Hubungan timbal balik antara pedalaman (Dieng-Gedongsongo) dengan daerah pesisiran (Pekalongan-Batang) sudah terjadi sejak awal perhinduan 
wilayah Jawa Tengah. Berkembangnya wilayah Pekalongan-Batang dalam budaya tentu saja diikuti perkembangan perdagangan antar wilayah, akibatnya terbukanya pelabuhan-pelabuhan di sepanjang pantai Pekalongan-Batang. Sehingga tidak diragukan lagi bahwa pada abad VII atau VIII Mtelah terjadi hubungan erat antara kedatuan Sriwijaya dengan kerajaan Jawa Tengah, khususnya dalam bidang bahasa.

\section{c. Laguna}

Pernah ditemukan sebuah prasasti berbahasa Melayu-Kuna di pantai selatan Laguna (Pilipina). Prasasti itu berupa selembar lempengan tembaga, ditulisi hanya sebelah sisinya, berhuruf Jawa-Kuna, bertahun 822 C. Oleh karena prasasti itu lempengan tembaga (bersifat labil), maka keberadaannya di sana masih perlu dipertanyakan. Mungkin prasasti ini dibawa seorang Indonesia yang berpindah tempat di Laguna. Meskipun demikian dapat diasumsikan bahwa bahasa Melayu-Kuna pernah sampai di Laguna (Pilipina)

Dari uraian di atas dapat dikatakan bahwa bahasa Melayu-Kuna sebagai bahasa ibu penduduk Sriwijaya pernah tersebar sampai di Jawa Tengah, Jawa Barat, dan Laguna (Pilipina).

\section{Tinjauan dari aspek waktu}

Dari prasasti-prasasti berbahasa Melayu-Kuna yang berangka tahun dapat direkonstruksi tentang kapan terjadinya persebarannya. Bahasa Melayu-Kuna memang telah menjadi bahasa ibu masyarakat Sriwijaya disamping bahasa Sanskerta. Oleh karena itu prasasti-prasasti yang dikeluarkan oleh kedatuan Sriwijaya dengan bahasa Melayu-Kuna memang sudah pada tempatnya; seperti halnya prasasti-prasasti raja-raja Jawa menggunakan bahasa Jawa-Kuna bercampur dengan bahasa Sanskerta.

Prasasti Kedukan Bukit 605 C merupakan prasasti tertuadari kedatuan Sriwijaya, diikuti prasasti Talang Tuwo bertahun 606 Ç (keduanya ditemukan di Palembang). Selanjutnya prasasti Karang Birahi (ditemukan di Jambi), prasasti Kota Kapur 608 C ditemukan di Pulau Bangka, dan prasasti yang tidak berangka tahun ditemukan di wilayah Lampung. Tiga buah prasasti yang berbahasa Melayu-Kuna dan berangka tahun ditemukan di Jawa yaitu prasasti Manjuçrigrha 714 C (ditemukan di Candi Sewu, Prambanan). Prasasti Dang $\mathrm{Pu}$ Hawang Glis $749 \mathrm{C}$ (ditemukan di Temanggung). Dari prasasti Manjuçrigrha didapat kesan bahwa paling lambat sejak tahun 719 C bahasa Melayu-Kuna telah berkembang di Jawa Tengah. 
Sebuah prasasti berbahasa Melayu-Kuna yang ditemukan di Kebon Kopi (Jawa Barat angka tahunnya berupa kalimat (seperti sengkalan tetapi untuk menemukan angka tahunnya tanpa dibalik membacanya) yaitu kawihaji pañca pasagi atau $856 \mathrm{C}$ (FDK. Bosch, 1941: 49-53). Karena hanya sebuah prasasti saja yang ditemukan, maka keberadaan bahasa Melayu-Kuna di Jawa Barat kurang jelas prosesnya. Dilihat dari waktunya, maka perkembangan bahasa Melayu-Kuna di Jawa Tengah lebih awal dibandingkan dengan di Jawa Barat. Bila dilihat dari segi ruangnya, mestinya Jawa Barat lebih banyak mempunyai prasasti berbahasa Melayu-Kuna dan lebih awal bila dibandingkan dengan Jawa Tengah. Kenyataannya tidak demikian. Jadi hukum getaran orang melempar batu di permukaan air (daerah di dekat sumber getaran akan mendapat getaran yang paling kuat) tidak berlaku untuk peristiwa perkayaan kebudayaan.

\section{Tinjauan Dari Segi Kebahasaan}

Sejarah meliputi ruang, waktu, gejala, hubungan, dan peristiwa secara utuh dan terpadu. Secara keseluruhan bahasa Melayu-Kuna yang ada pada prasasti-prasasti dari Sumatera tidak ada bedanya dengan bahasa Melayu-Kuna yang ada dari prasastiprasasti dari Jawa atau dari Laguna. Namun demikian bentuk klise (stereotif) yang ada pada prasasti-prasasti dari Sumatera tidak sepenuhnya ada atau sama sekali tidak dipergunakan pada prasasti-prasasti di Jawa. Pada awal prasasti Kota Kapur atau Telaga Batu misalnya terdapat beberapa baris kalimat yang disebut oleh L.Ch. Damais Bahasa B prasasti Sriwijaya (Damais, 1989: 139) yaitu dari kata Siddha kitan ..... sampai dengan kata ni humpa unai tunai . Kata-kata yang ada di Bahasa B ini memang sulit diartikan. L.Ch. Damais mencoba mengartikan kata-kata itu sehingga dapat menterjemahkan sementara arti yang tersirat pada prasasti (Damais, 1989: 185). Dilihat dari isinya, kalimat pada Bahasa B tidak dapat disebut sebagai manggala sebab manggala pada prasasti maupun kesastraan biasanya berisi sanjungan atau pujaan yang ditujukan kepada dewa atau raja. Sedangkan isi kalimat Bahasa B bernafaskan ancaman atau kutukan. Prasasti-prasasti berbahasa Melayu-Kuna yang berasal dari Jawa tidak mengenal kalimat Bahasa B itu, tetapi justru diawali dengan manggala misalnya: namaç̧iwaya om nahajana (S.H. Wintang).

Isi suatu prasasti ikut menentukan jenis atau pilihan kata yang akan dipergunakan. Prasasti-prasasti dari masa kedatuan Sriwijaya kebanyakan berisi kutukan, oleh karena itu mulai dari awal kalimat (Bahasa B)hingga kalimat terakhir penuh dengan kata yang bernafaskan mengerikan. Berbeda dengan bahasa Melayu-Kuna yang ada di prasasti-prasasti yang ditemukan di Jawa. Dilihat dari isinya, prasasti-prasasti berbahasa Melayu-Kuna di Jawa membicarakan tentang silisilah (S.H. Wintang), perluasan bangunan (Manjuçrigrha), dan inventarisasi barang milik dewa 
(Dewadrabya). Sehingga bahasa yang dipergunakanadalah bahasa yang halus tidak bernafaskan menyeramkan.

Secara morfologis bahasa Melayu-Kuna di Jawa mengalami perkembangan. Awalan war- (yang dalam perkembangannya nanti menjadi awalan ber-) mulai dipergunakan. Awalan war- merupakan perkembangan awalan mar- di Jawa misalnya kata marapuy $=$ berapi dan $\mathbf{m a r a w u}=$ berabu. Demikian awalan di- untuk membuat bentuk pasif makin banyak dipergunakan di samping sisipan -in-.

Susunan kata majemuk bhümi jawa dari prasasti Kota Kapur (Kota Kapur, 608 Ç:10) dapat dibandingkan dengan kata majemuk dwipe jawakhye dari prasasti Canggal (Canggal, 654 Ç:8). Apabila mengikuti sistem bahasa Sanskerta (hukum MD), maka kata jawa kata pokoknya, sedang kata bhümi (tanah) dan dwipe (pulau) adalah keterangan. Jadi bhümi jawa (tanah Jawa) dan dwipe jawakhye adalah lokatif bukan nama diri. Jadi bhümi jawa bukan nama diri (daerah yang bernama bumi Jawa sekarang yang ada di Sumatra) melainkan tanah Jawa seperti halnya pulau Jawa dari prasasti Canggal.

\section{Tinjauan Dari Segi Kesejarahan}

Usaha keras Sriwijaya dalam meluaskan wilayahnya tampak dari beberapa prasastinya. Di dalam prasasti Kedukan Bukit $604 \mathrm{C}$ terdapat tiga babakan yang dilaksanakan oleh Dapunta Hyang untuk meluaskan wilayahnya. Pertama, pada tanggal 11 paroh terang bulan Waiçakha 608 Ç Dapunta Hyang dengan naik perahu mengadakan perjalanan untuk mencari siddhatastra. Kedua, pada tanggal 7 paroh terang bulan Jestha (608 Ç) Dapunta Hyang dengan bala tentara (ada yang naik perahu dan ada yang jalan kaki) dari Minana Tamwan menuju mukha..p... Ketiga, pada tanggal 5 bulan terang bulan (?) datang di (nama daerahnya tidak disebut), dan di sini ia membangun desa (wanua) (Buchari, 1986: ...). Keberhasilan usaha Sri Jayanasa ditandai dengan pembangunan taman di Sri Ksetra (Talang Tuwo). Kedua prasasti ini mengisyaratkan bahwa peristiwa sejarah tersebut terjadi di wilayah Palembang:

Usaha perluasan wilayah kedatuan Sriwijaya ke arah utara ditujukan ke Jambi. Ia mengalahkan kerajaan Melayu, seperti berita I-tsing sepulang dari India mengatakan bahwa Melayu sudah menjadi bagian dari kerajaan Sriwijaya. Perluasan wilayah diteruskan ke arah Kedah (Semenanjung Malaka) dan Muangthai (prasasti Ligor) (Nia Kunia, 1983: 59).

Perluasan wilayah kedatuan Sriwijaya ke selatan diarahkan ke daerah Lampung. Hal ini ditandai dengan beberapa prasasti yang ditemukan di daerah ini antara lain prasasti 
Telaga Batu. Pakas Pasemah, Boom Baru. Prasasti Kota Kapur sebagai tanda bahwa pulau Bangka telah menjadi wilayah kedatuan Sriwijaya pada tahun $608 \mathrm{C}$, bahkan ada usaha perluasan wilayah ke arah Jawa.

Lemahnya kerajaan Tarumanagara (di Jawa Barat) dan kerajaan Sanna (di Jawa Tengah bertetangan dengan kerajaab Galuh) (certita Parahyangan; Canggal $654 \mathrm{C}$ : $9,10,11)$ menjadikan perhitungan kedatuan Sriwijaya untuk menjamah wilayah ini. Yang menjadi masalah ialah pernahkah ada armada perang atau ekspedisi Sriwijaya yang mendarat di Jawa? Apabila tidak terjadi serangan Sriwijaya ke Jawa, bagaimana makna kalimat terakhir prasasti Kota Kapur? Kenyataannya di Jawa ditemukan beberapa prasasti berbahasa Melayu-Kuna, ini pertanda adanya kontak antara Sriwijaya dengan Jawa. Masalahnya bentuk kontak yang bagaimana pernah antara Sriwijaya dengan Jawa?

Sampai sekarang belum ada sumber baik prasasti maupun kesastraan yang menyebut bahwa Sriwijaya pernah menyerang Jawa. Seandainya pernah terjadi serangan itu, tentu ada data yang menjelaskan lebih jauh (tidak hanya seperti kalimat terakhir dari prasasti Kota Kapur), atau ada lawan balik dari raja Jawa ketia ia mencapai kejayaannya, ataupun mungkin bahasa Melayu-Kuna tidak akan berkembang di Jawa (bahkan sampai dipergunakan untuk menulis prasasti).

Setelah kerajaan Tarumanagara runtuh, kerajaan Galuh (perkembangan selanjutnya menjadi kerajaan Sunda) mengalami kemajuan. Demikian juga keruntuhan kerajaan Sanna tidak berarti berakhimya kerajaan Jawa Tengah, sebab Sanjaya sebagai penggantinya dan mengalami perkembangan. Keadaan inilah yang diperhitungkan Sriwijaya untuk mengurungkan menyerang Jawa. Sedangkan makna kalimat terakhir prasasti Kota Kapur yang selengkapnya berbunyi: Kaliwat manapik yam bhümi jawa tida bhakti ka crïwijaya (artinya: sangat berusaha memukul tanah Jawa "jika" tidak setia kepada Sriwijaya) lebih bersifat ancaman, belum merupakan tindakan yang telah dilakukan.

Adanya bahasa Melayu-Kuna di Jawa bukan merupakan akibat serangan Sriwijaya terhadap Jawa, melainkan merupakan hasil proses perkayaan budaya (khususnya dalam bidang bahasa). Dari proses awal hingga bahasa Melayu-Kuna dipergunakan untuk menuliskan prasasti tentu memerlukan waktu lama.

Fungsi bahasa sebagai alat komunikasi antar manusia atau bangsa. Bahasa MelayuKuna di Sriwijaya tidak hanya untuk kepentingan kelancaran pemerintah, tetapi juga untuk komunikasi di bidang ekonomi dan juga bidang agama. Hal ini berkaitan pulau Jawa dan Sumatera terletak di jalur perdagangan dan route para peziarah yang akan pergi pulang ke (dari) India. Selat Malaka sejak abad V telah merupakan jalur pelayaran para biarawan maupun para pedagang. Fahien tahun 414 ketika pulang dari 
India mengunjungi Jawa (Groeneveldt, 1960: 6). I-tsing pernah singgah di Jawa, demikian juga Hwu-ning pada tahun 664/665 (Poerbatjaraka, 1952: 19). Para peziarah itu tentu mampu berbahasa anak negeri yang didatangi (sebab ia datang di tanah yang dikunjungi dalam waktu yang tidak singkat). Juga para pedagang yang berkelana baik ke Jawa, Sumatera maupun ke Semenanjung Malaka tentu pandai berbahasa MelayuKuna. Orang Cina menyebut bahasa yang dipergunakan mereka (para pedagang) ialah bahasa Kwun-lun. Tentu saja yang dimaksud bahasa Kwun-lun adalah bahasa Melayu-Kuna yang bercampur bahasa Sanskerta (Poerbatjaraka, 1952: 22).

Istilah Kwun-lun dipergunakan juga untuk menamai pulau Kondor, tanah Campa, Kabuja, Burma, daerah Cina selatan, Madagaskar, dan pantai timur Afrika Timur (Poerbatjaraka, 1952: 22). Jadi Kwun-lun merupakan bahasa esperanto terutama untuk kepentingan perdagangan dan peziarahan di wilayah tersebut di atas.

Sejak abad VII di Jawa telah ada tiga macam bahasa yang dipergunakan oleh penduduk, yaitu bahasa Jawa-Kuna (bahasa ibu), bahasa Sanskerta (terutama untuk kepentingan keagamaan), dan bahasa Melayu-Kuna (awalnya untuk kepentingan perdagangan). Adanya loncatan bahasa Melayu-Kuna dari bahasa untuk kepentingan perdagangan dipergunakan oleh para peziarah dan menjadi bahasa untuk penulisan prasasti merupakan hal yang menarik dan menjadi suatu masalah tersendiri.

Di Jawa prasasti selalu dikeluarkan oleh raja atau pejabat kerajaan baik ia bergelar rakai atau pamgat atau bergelar keagamaan. Hal ini menimbulkan beberapa pendapat tentang asal usul dinasti Selendra yang ada di Jawa, ia juga mengeluarkan prasasti. N.J. Krom mengatakan raja-raja di Jawa Tengah tidak lain adalah raja-raja Sriwijaya, sebab Jawa Tengah berada di dalam kekuasaan dinasti Sailendra (Nia Kurnia, 1982: 69: Krom, 1919).

Teori Krom ini dibantah oleh W.F. Stutterheim, ia mengatakan bahwa justru kerajaan Jawa yang dapat menaklukkan kerajaan Sriwijaya (Nia Kurnia, 1982: 69; Stutterheim, 1929). R.C. Majumdar dan K.A. Nilakantasastri mengatakan dinasti Sailendra berasal dari India (Nia Kurnia, 1982: 70; Majumdar, 1933: 121-141; Nilakantasastri, 1935: 605-661). G. Coedes dan F.D.K. Boscb mengatakan dinasti Sailendra berasal dari Funan (Coedes 1934: 66-70; Bosch, 1952: 113-123). Buchari berdasarkan prasasti Sojomerto berpendapat bahwa dinasti Sailendra adalah bangsa Indonesia asli (Buchari, 1966: 241-251). Buchari tidak menyebut dari daerah mana ia berasal. Nia Kurnia mendasarkan kesamaan bahasa antara prasasti dari Sriwijaya dan prasasti berbahasa Melayu-Kuna dari Jawa (kata sida dipakai di Sriwijaya dan di Jawa) menyimpulkan bahwa dapunta Sailendra berasal dari Sriwijaya (Nia Kurnia, 1982: 71). 
Dalam sistem pemerintahan yang bersifat kerajaan tidak mudah ditembus dari luar, apalagi penembus akan menjadi pejabat. Jadi tidak mungkin orang dari Sriwijaya masuk dalam kalangan pejabat kerajaan Jawa dan mengeluarkan prasasti. Di lain pihak proses perkayaan bahasa Melayu-Kuna di Jawa sudah berjalan sebelum prasasti itu ditulis. Jadi apabila prasasti Sajamerta yang berasal dari abad VII M sebagai awal dinasti Sailendra di Jawa, berarti bahasa Melayu-Kuna telah dikenal sebelumnya. Dari uraian singkat ini didapat petunjuk bahwa Dapunta Sailendra adalah orang Jawa, berasal Siwaistis, dan mahir berbahasa Melayu-Kuna, dan ia masih termasuk kerabat raja Jawa.

\section{Kesimpulan}

a. Bahasa Melayu-Kuna sebagai bahasa ibu kedatuan Sriwijaya, pada abad VII M berkembang di Jawa.

b. Keberadaan bahasa Melayu-Kuna di Jawa merupakan hasil proses perkayaan budaya.

c. Dapunta Sailendra (pendukung bahasa Melayu-Kuna) adalah Jawa, ia masih termasuk keluarga raja Jawa, dan ia mahir berbahasa Melayu-Kuna.

d. Bahasa Melayu-Kuna merupakan awal atau induk bahasa Indonesia. 


\section{KEPUSTAKAAN}

Bosch. F.D.K. 1941. "Een Maleische lnscriptie in hot Buitenzerggsch"', BKI. 100: 49-53.

Bosch. F.D.K. 1952. "Criwijaya. de Cailendra en de Sanjayawamca. BKI. 108: 113-123.

Brandes. J. L.A. I 91 3. Oud-Javaansche Oorkonden. Martinus Nijhoff. ·sGravenhagc. Batavia.

Buchari. 1966. "Preliminary Report on the Discovery of an Old-Malay Inscription at Sodjomerto. MISI III (2.3).

Buchari. 1979. "An Old Malay Inscription of Srivijaya at Palas Pasemah (South Lampung). Pra Seminar Penelitian Sriwijaya. Pusat Penelitian Arkeologi Nasional.

Buchari. 1986. "New Investigation on the Kedukan Bukit Inscription". Untuk Bapak Guru: Persembahan Para Murid Bernet Kempers. Jakarta: 33-56.

Casparis. J.G. de. 1950. Inscripties ui de Cailendra-Tijd (Prasasti Indonesia I), Nix, Bandung.

Casparis. J.G. de. 1956. Selected Inscriptions from the 7 th to 9 th Century A.D (Prasasti Indonesia II). Dinas Purbakala Republik Indonesia, Masa Baru, Bandung.

Coedes. G. 1918. “Le Royaume de Crivijaya” BEFEO. tomeXVIII (6): 1-36.

Coedes. G. 1930. "'Les Inscriptions Malaise de Criwijaya. BEFEO, tome XXX: 29-80 (terjemahan: "Prasasti Berbahasa Melayu Kerajaan Sriwijaya". Kedatuan Sriwijaya. Dep.dik.bud. 1989: 49-110).

Coedes. G. 1934. "'On the Origin of the Cailendra of Indonesia. JGIS, I.

Damais. L.Ch. 1968. "La Langue B des Inscriptions de Sri Wijaya ". BEFEO, LIV: 523-566 (terjemahan: "Bahasa B Prasasti Sriwijaya", Kedatuan Sriwijaya, Dep.dik.bud. I 989: 139-205).

Krom. N .J. 1919. De Sumatraanche Periode des Javaansche Geschiedenis, E.J. Brill. Leiden. 
Krom. N .J. 1920. ·De Inscriptie van Karang Brahi. TBG: 59.

Majumdar, R.C, 1933. "Le Raois Cailendra de Suwarnadwipa ", DEFEO, XXXIII.

Nia Kurnia Sholihat lrfan, 1982. Kerajaan Sriwijaya. Jakarta: PT: Djaja Pirusa.

Poerbatjaraka, M.R.Ng, 1952. Riwayat Indonesia I. Jakarta: Yayasan Pembangunan.

Poerbatjaraka, M.R.Ng. 1958. "Criwijaya de Cailendra- en de Sanjayawamca. BKI, 114.

Atmodjo, S. K. (1994). Beberapa Temuan Prasasti Baru Di Indonesia. Berkala Arkeologi, 14(2), 1-5. https://doi.org/10.30883/jba.v14i2.630

Sukmono, R, 1964. "Pemeliharaan dan Penggunaan Bahasa-bahasa Sejarah ", MISI, II (I).

Stutterheim. W.F. 1929. A Javanese Period in Sumatra History. Surakarta: De Bliksem.

Wolters, O.W, 1970. The Fall of Sriwijaya in Malay History. Kualalumpur: Oxford Univ. Press.

Yuanzhi, Kong, 1933. “Bahasa Kunlun Dalam Sejarah Perkembangan Bahasa Melayu”. Simposium Internasional Ilmu-ilmu Humaniora II. Yogyakarta 